\title{
Genetic Variability and Divergence Analysis in Rice (Oryza sativa L.) under Sodic Soil
}

\author{
B.K. Maurya*, P.K. Singh, O.P. Verma and D.K. Mandal \\ Department of Genetics and Plant Breeding, N D University of Agriculture and Technology \\ Kumarganj, Faizabad-224229 (UP), India \\ *Corresponding author
}

\section{A B S T R A C T}

The present investigation was comprised of 30 lines of rice Germplasm along with three checks viz., Narendra Usar 3, Sarjoo 52 and IR 28. The material, comprising indigenous as well as exotic germplasm lines, exhibited wide spectrum of variation for various

Keywords Rice, $\mathrm{D}^{2}$, Cluster.

Article Info

Accepted: 23 September 2017 Available Online: 10 October 2017 agronomic and morphological characters. In the study, genetic divergence among 33 genotypes of rice under sodic soil was performed by employingD ${ }^{2}$ statistics and Nonhierarchical Euclidean cluster analysis as described by Beale (1969) and Spark (1973). The 33 genotypes were grouped into 6 different non-overlapping clusters. Cluster II, containing 11 genotypes, emerged with highest number of genotypes, while cluster III with 6 genotypes contained second highest number of entries among 6 clusters. Cluster I was represented by 5 genotypes. Cluster IV and cluster $\mathrm{V}$ also possessed 5 entries each. Cluster VI with one genotype had lowest number of entries. The discrimination of lines into so many discrete clusters suggested presence of high degree of genetic diversity in the material evaluated. Presence of substantial genetic diversity among the lines screened in the present study indicated that this material may serve as good source for selecting the diverse parents for hybridization programme aimed as isolating desirable segregates for developing high yielding varieties of rice suitable for sodic soil.

\section{Introduction}

Rice (Oryza sativa L.) is the most important staple food crop of the world because of being the major source of calories of more than half of the total global population. The importance of rice is not only as a fundamental commodity and primary food source for more than half of the world's population, but also as emerges from the complex rice based ecosystems that influence issues of global concern such as food security and development. More than 90 per cent of the world's rice is grown and consumed in Asia, known as rice bowl of the world, where 60 per cent of the earth's people and two third of world's poor live (Khush and Virk, 2000). Rice being the staple food for more than 70 per cent of our national population and source of livelihood for 120-150 million rural households, is backbone to the Indian Agriculture. Rice is cultivated world-wide over an area of about 156.68 million hectares with an annual production of about 680.19 million tonnes with an average productivity of 5.15 tonnes per hectare (Anonymous, 2014). India is the largest rice growing country, while China is the largest producer of rice. In 
India, during 2014-15 the rice crop had production of $103.04 \mathrm{mt}$. However, in Uttar Pradesh it was grown on 5094 mha with production of $15.30 \mathrm{mt}$. The average productivity of Uttar Pradesh is $257.3 \mathrm{~kg} / \mathrm{ha}$ which is more than the national average productivity (Anonymous, 2014).

Although, the average productivity of rice is much lower in India than the average productivity at world level. The development of high yielding, widely adapted pureline rice varieties coupled with advances in production technology in past four decades has enabled us to cope up with the demand of rice to a satisfactory level. However, rapidly increasing demand due to ever increasing Indian population has forced us to search for another quantum jump in rice production. The projection of India's rice production target for 2020 AD is 115-120 million tonnes, which can be achieved only by increasing the rice production by over 2.0 million tonnes/year in the coming decade (Viraktamath and Shobha Rani, 2008). This has to be done against backdrop of diminishing natural resource bases like land, labour and water, which is a huge challenge (Subbiah, 2006). Considering the rapidly decreasing availability of agricultural land due to urbanization and industrialization, utilization of different ecosystems and under exploited stress environments for rice production would be needed. Thus, adoption of high yielding rice varieties to various stress environments and under-utilized lands such as sodic and other problem, soils would be an important strategy to meet this challenge.

Every year more and more land is becoming non-productive because of salt accumulation in soil in coastal as well as certain inland saline tracks. Salinity is a serious problem affecting 1/3 of all irrigated land in the world. Nearly, 6.73 million hectares of soils in India are salt affected and categorized into two broad groups alkali and saline soils. Recent estimates indicate that more than 1.5 million hectares of salt affected area has been reclaimed and is contributing about 10 million tonnes additional food grains to the central pool. At present, in Indo-gangetic plains in India, a total of 2.348 million hectares area is salt affected in which Uttar Pradesh has a share of 1.37 million hectares.

In order to step up the production potential, there is, thus, an urgent need to launch dynamic breeding programmes to develop rice varieties suitable for different agroclimatic regions, normal and stress environments. Substantial genetic variability is essential for initiating an effective breeding programme and therefore, it becomes imperative to evaluate the level of genetic variability existing in the crop germplasm collections to identify promising lines for exploitation as donor parents in recombination breeding programmes.

\section{Materials and Methods}

The present investigation was carried out during kharif, 2015. at Genetics and Plant Breeding farm of Narendra Deva University of Agriculture and Technology, Narendra Nagar, (Kumarganj), Faizabad (U.P.), India. Geographically, Narendra Nagar is situated between $26.47^{\circ} \mathrm{N}$ latitude and $82.12^{\circ} \mathrm{E}$ longitude and at an altitude of 113 meters above the mean sea level in the gangatic plains of eastern U.P. The climate of district Faizabad is semi-arid with hot summer and cold winter. The soil type of experimental site was silty loam, low in organic carbon, nitrogen, phosphorus and rich in potash. The soil of the experimental site was partially reclaimed sodic soil $\left\{\mathrm{ECe}=2.21\left(\mathrm{dSm}^{-1}\right)\right.$; $\mathrm{pH}=9.27\}$. The experimental material for the present investigation was comprised of 30 lines of rice Germplasm along with three checks viz., Narendra Usar 3, Sarjoo 52 and 
IR 28. The material, comprising indigenous as well as exotic germplasm lines, exhibited wide spectrum of variation for various agronomic and morphological characters. All the 30 genotypes were grown during "kharif" season of 2015 under irrigated condition. The experimental material was sown and transplanted on 05.07.2015 and 06.08.2015, respectively. The 33 entries were evaluated in Randomized Complete Block Design with 3 replications under sodic soil during kharif, 2015. Each genotype/treatment was grown by transplanting single seedling per hill in single row plots of 3 meter length following interrow and intra-row spacing of $20 \mathrm{~cm}$ and 15 $\mathrm{cm}$, respectively. The electrical conductive and $\mathrm{pH}$ of the experimental plot were measured using standard procedure. The recommended cultural practices were followed to raise a good crop. Data were recorded on twelve yield contributing characters viz. Days to $50 \%$ flowering, Days to maturity, Plant height $(\mathrm{cm})$, Flag leaf area $\left(\mathrm{cm}^{2}\right)$, Panicle length $(\mathrm{cm})$, Effective tillers per plant, Spikelets per panicle, Spikelet fertility (\%),1000-grain weight (g), Biological yield per plant (g), Harvest index (\%), Grain yield per plant $(\mathrm{g})$. Data recorded on the above characters were subjected to estimate the genetic diversity using $\mathrm{D}^{2}$ statistics (Mahalanobis) and Non-hierarchical Euclidean cluster analysis as described by Beale (1969) and Spark (1973).

\section{Results and Discussion}

The study of genetic divergence among 33 genotypes of rice under sodic soil was performed by employing Non-hierarchical Euclidean cluster analysis as described by Beale (1969) and Spark (1973). The 33 genotypes were grouped into 6 different nonoverlapping clusters as presented in Table 1 .

Cluster II contained highest number of 11 genotypes, followed by cluster III with 6 genotypes. Cluster I, IV and V contained 5 genotypes each. Cluster VI was constituted by single genotype to emerge as cluster with least numbers of entries. The discrimination of lines into so many discrete clusters suggested presence of high degree of genetic diversity in the material evaluated. Earlier workers have also reported existence of substantial genetic divergence in rice materials such as Devi et al., (2006), Kumar, (2008), Parimalan et al., (2008), Ramya and Senthilkumar, (2008), Ishfaq et al., (2009) and Rouf et al., (2009), Pratap et al., (2011), Ovung et al., (2012), Arivoli et al., (2013) and Mahalingam et al., (2013).

The estimates of intra-and inter-cluster distances values have been depicted in Table 2. The intra-cluster distances ranged from 0.00 (cluster VI) to 19.70 (cluster IV). The maximum inter-cluster distance was observed between cluster V and VI (98.08), followed by cluster I and VI (85.93). Besides, cluster VI also exhibited very high inter cluster distances with cluster II (73.94), cluster III (58.45) and cluster IV (53.74). High order inter cluster distances were also observed between cluster IV and V (36.24), cluster III and IV (25.15) and cluster III and V (25.12). The minimum estimate for inter-cluster distance was recorded between cluster I and II (15.80), followed by cluster I and III (18.30), cluster II and III (19.92), cluster V and I (20.63), cluster II and IV (23.04) and cluster I and IV (24.08).The crosses between genotypes belonging to clusters separated by low inter-cluster distances are unlikely to throw promising recombinants in the segregating generations.

So crossing between the genotypes belonging to cluster pairs separated by larger intracluster distances from one or another character to be improved is likely to be more fruitful. In this context, cluster VI, having 1 genotype, showed very high inter-cluster 
distances from cluster I, II, III, IV and V. This finding is in conformity with the previous reports advocating lack of parallelism between genetic and geographic diversity in rice by Deepsankar et al., (2005),
Vaithiyalingan (2005), Chandra et al., (2007), Kumar (2008), Raut et al., (2009), Rouf et al., (2009), Pratap et al., (2011), Ovung et al., (2012), Arivoli et al., (2013), Mahalingam et al., (2013) and Panday et al., (2015).

Table.1 Clustering pattern of 30 genotypes and 3 checks of rice (Oryza sativa L.) on the basis of non-hierarchical Euclidean cluster analysis

\begin{tabular}{|c|c|l|}
\hline Clusters & No. of genotypes & \multicolumn{1}{|c|}{ Genotypes } \\
\hline I & 5 & $\begin{array}{l}\text { IR84645-281-10-B-B, Sarjoo 52, IR84645-191-5-1-B, } \\
\text { IR84645-320-21-1-B, IR84645-81-5-B-B }\end{array}$ \\
\hline II & 11 & $\begin{array}{l}\text { IR84645-305-6-1-B, IR84645-321-7-1-B, NDRK 50063, } \\
\text { Narendra Usar 3, IR 29, IR84645-311-5-1-1-B, NDRK 501, } \\
\text { IR84645-88-5-1-B, IR84645-308-70-1-B, IR 64, FL 478 }\end{array}$ \\
\hline III & 6 & $\begin{array}{l}\text { IR84645-81-10-B-B, IR84645-275-4-1-B, IR84645-129-5-1- } \\
\text { B, IR84645-275-3-2-B, Nrendra Usar 2009, IR 28 }\end{array}$ \\
\hline IV & 5 & $\begin{array}{l}\text { IR84645-308-69-1-B, BW 267-3, Swarna sab 1, CSR 43, } \\
\text { IR84645-320-3-1-B }\end{array}$ \\
\hline V & 5 & $\begin{array}{l}\text { IR84645-291-1-1-B, Kalanamak, IR84645-292-3-1-B, CSR } \\
\text { 36, Kalanamak 3 }\end{array}$ \\
\hline VI & 1 & IR84645-95-1-1-B \\
\hline
\end{tabular}

Table.2 Estimates of average intra and inter-cluster distances for 6 clusters in rice (Oryza sativa L.)

\begin{tabular}{|c|c|c|c|c|c|c|c|}
\hline S.No. & Clusters & I & II & III & IV & V & VI \\
\hline $\mathbf{1 .}$ & I & $\mathbf{5 . 7 7}$ & 15.80 & 18.30 & 24.08 & 20.63 & 85.96 \\
\hline $\mathbf{2 .}$ & II & & $\mathbf{1 4 . 4 6}$ & 19.92 & 23.04 & 24.94 & 73.94 \\
\hline 3. & III & & & $\mathbf{1 3 . 9 3}$ & 25.15 & 25.12 & 58.45 \\
\hline $\mathbf{4 .}$ & IV & & & & $\mathbf{1 9 . 7 0}$ & 36.24 & 53.74 \\
\hline $\mathbf{5 .}$ & V & & & & & $\mathbf{1 5 . 6 2}$ & 98.08 \\
\hline 6. & VI & & & & & & $\mathbf{0 . 0 0}$ \\
\hline
\end{tabular}

Bold figures represent intra-cluster distance.

Table.3 Cluster means for 12 characters of rice (Oryza sativa L.)

\begin{tabular}{|c|c|c|c|c|c|c|c|c|c|c|c|c|}
\hline Cluster & $\begin{array}{c}\text { Days to } \\
50 \% \\
\text { flowering }\end{array}$ & $\begin{array}{c}\text { Plant } \\
\text { height } \\
\text { (cm) }\end{array}$ & $\begin{array}{l}\text { Flag } \\
\text { leaf } \\
\text { area } \\
\left(\mathrm{cm}^{2}\right)\end{array}$ & $\begin{array}{c}\text { Effective } \\
\text { tillers } \\
\text { per } \\
\text { plant }\end{array}$ & $\begin{array}{c}\text { Panicle } \\
\text { length } \\
\text { (cm) }\end{array}$ & $\begin{array}{c}\text { Spikelets } \\
\text { per } \\
\text { panicle }\end{array}$ & $\begin{array}{c}\text { Grains } \\
\text { per } \\
\text { panicle }\end{array}$ & $\begin{array}{c}\text { Spikelet } \\
\text { fertility } \\
(\%)\end{array}$ & $\begin{array}{c}\text { 1000- } \\
\text { grain } \\
\text { weight } \\
\text { (g) }\end{array}$ & $\begin{array}{c}\text { Biologica } \\
\text { l yield } \\
\text { per plant } \\
\text { (g) }\end{array}$ & $\begin{array}{c}\text { Harvest } \\
\text { index } \\
(\%)\end{array}$ & $\begin{array}{c}\text { Grain yield } \\
\text { per plant }(\mathrm{g})\end{array}$ \\
\hline I & 95.76 & 100.62 & 25.29 & $10.82 *$ & 24.49 & $98.78 *$ & $84.76^{*}$ & 85.71 & 26.25 & 32.30 & $39.23^{*}$ & 12.66 \\
\hline II & 91.78 & 93.43 & $19.82 *$ & 12.86 & 23.65 & 125.96 & 105.16 & $83.59 *$ & 25.60 & 30.53 & 41.36 & 12.65 \\
\hline III & 96.13 & 99.66 & 25.08 & 12.29 & $25.65 * *$ & 153.85 & 133.41 & $87.05 * *$ & 25.68 & 30.75 & 42.60 & 13.27 \\
\hline IV & 93.70 & $90.06^{*}$ & 22.12 & 13.13 & $22.87 *$ & 145.75 & 124.48 & 85.08 & 24.68 & 45.75 & 40.22 & 18.44 \\
\hline V & $103.61 * *$ & $120.57 * *$ & 20.83 & 10.98 & 23.07 & 114.81 & 98.13 & 85.50 & $23.04 *$ & $27.05 *$ & 42.47 & $11.50 *$ \\
\hline VI & $89.27 *$ & 114.67 & $28.20 * *$ & $20.00 * *$ & 25.39 & $223.65^{* *}$ & $189.60^{* *}$ & 84.81 & $29.12 * *$ & $56.49 * *$ & $44.51 * *$ & $25.27 * *$ \\
\hline
\end{tabular}


The intra cluster groups means for 12 characters, given in Table 3 revealed marked differences between the clusters in respect of cluster means for different characters. Cluster VI, having single entry, showed highest cluster means for flag leaf area $\left(28.19 \mathrm{~cm}^{2}\right)$,panicle bearing tillers per plant (20.00), spikelets per panicle (223.67), grains per panicle (189.60), 1000- grain weight $(29.11 \mathrm{~g})$, biological yield per plant $(56.49 \mathrm{~g})$ harvest Index $(44.50 \%)$ and grain yield per plant $(25.26 \mathrm{~g})$ and showed lowest mean for days to 50\%flowering (89.27) Cluster VI also recorded second highest cluster means for plant height $(114.67 \mathrm{~cm})$ and panicle length (25.3).

The 5 genotypes of cluster $\mathrm{V}$ were responsible for highest cluster means for days to $50 \%$ flowering (103.60), and plant height $(125.56 \mathrm{~cm})$ besides showing lowest means for 1000- grain weight $(23.04 \mathrm{~g})$, biological yield per plant (27.05) and grain yield per plant $(11.49 \mathrm{~g})$. Cluster V was characterized by low to moderate cluster means for rest of the characters.

Cluster III, having 6 genotypes showed highest cluster means for panicle length $(25.65 \mathrm{~cm})$ and spikelet fertility $(87.05 \%)$. While having medium to high cluster mean for remaining characters.

Cluster I, having 5 genotypes exhibited in desirable lowest cluster means for Panicle bearing tillers per plant (10.81), spikelets per panicle (98.78), grains per panicle (84.75) and harvest index (39.22\%) least had moderate to high means for other characters. Cluster II exhibited lowest cluster mean value for spikelet fertility (83.58) and flag leaf area $\left(19.82 \mathrm{~cm}^{2}\right)$ besides having low cluster means for remaining ten traits. The five genotype of were cluster IV having 5genotypes were responsible for lowest cluster means for plant height $(90.06 \mathrm{~cm})$ and panicle length $(22.87 \mathrm{~cm})$. Cluster IV exhibited second highest cluster means for panicle bearing tillers per plant (13.13), biological yield per plant (45.76) and grain yield per plant (18.44), but had low to medium means for remaining traits.

\section{References}

Anonymous, 2015. Statistical data base

Arivoli, V., Saravanan, K. and Prakash, M. 2013. A study on $\mathrm{D}^{2}$ analysis in rice. International Journal of Plant Sciences, Muzaffarnagar, 4(1): 157-160.

Deepsankar, P., Ibrahim, S.M.; Vivekanandan, P.; Anbumalarmathi, J. and Sheeba, A. 2005. Genetic divergence in rice ( $O$. sativa L.).Crop Res. (Hisar), 30 (3):428-431.

Kumar, B.M.D., 2008. Genetic divergence in red rice. Karnataka J. of Agril. Sciences, 21(3):346-348.

Panday, V.R., Singh, P.K.; Verma, O.P.; Yadav, P.K. and Singh, Y. 2015. Genetic divergence in exotic genotypes of rice (Oryza sativa L.) in salt affected soil. Res. Environ. Life Sci.8 (4) 812-814.

Parimalan, R., Joel, A.J. and Vanniarajan, C. 2008. Genotypes clustering in rice (Oryza sativa L.). Crop Improvement, 35(2): 115118.

Pratap, N., Singh, P.K.; Verma, G.P.; Kumar, Y. and Tripathi, S. 2011. Genetic divergence for yield and its components traits in aromatic and non-aromatic rice (Oryza sativa L.), Plant Archives, 11 (2): 801-804.

Raut, K. R., Harer, P. N. and Yadav, P. S. 2009. Genetic divergence in rice (Oryza sativa L.).J. Maharashtra Agril. Univ., 34 (2): 172-174.

Vaithiyalingan, M., 2005. Genetic divergence in rice (Oryza sativa L.). J. of Ecobiology, 17(4): 393-395.

\section{How to cite this article:}

Maurya, B.K., P.K. Singh, O.P. Verma and Mandal, D.K. 2017. Genetic Variability and Divergence Analysis in Rice (Oryza sativa L.) under Sodic Soil. Int.J.Curr.Microbiol.App.Sci. 6(10): 2865-2869. doi: https://doi.org/10.20546/ijcmas.2017.610.336 